\title{
Climate variability regulates population dynamics of a threatened freshwater fish
}

\author{
Zeb Tonkin ${ }^{1,2, *}$, Joanne Sharley ${ }^{1}$, Ben Fanson ${ }^{1}$, Scott Raymond $^{1}$, Renae Ayres ${ }^{1}$, \\ Jarod Lyon $^{1}$, Stephen Balcombe ${ }^{2}$, Nick Bond ${ }^{3}$ \\ ${ }^{1}$ Arthur Rylah Institute for Environmental Research, Department of Environment, Land Water and Planning, Heidelberg, \\ VIC 3084, Australia \\ ${ }^{2}$ Australian Rivers Institute, Griffith University, Nathan, QLD 4111, Australia \\ ${ }^{3}$ Centre for Freshwater Ecosystems, La Trobe University, Wodonga, VIC 3689, Australia
}

\begin{abstract}
Most predictions for the future climate in temperate ecosystems show longer periods of drought followed by more extreme precipitation events. These changes in flow regimes can strongly affect riverine fish populations; therefore, assessing the recovery of populations following these episodic events provides important information to help guide species management. This study investigated the dynamics of 5 spatially distinct riverine populations of the nationally endangered Macquarie perch Macquaria australasica in southeastern Australia from 2007-2018, a period that included the tail end of a decadal long drought followed by extreme fluctuations in river flow. Modelling catch rates and size trends, we found that 4 of the 5 populations showed some synchrony and underwent a slow recovery that was undetectable for several years. The largest increases in population size were driven by the survival of new recruits. Despite this general trend, we could only find a weak association between annual flow extremes and annual population change. This suggests intermediate variations in river flows may have a negligible influence on annual population change or are idiosyncratic in their effect within each waterway or on different life stages. The one population which did not follow this trend occurred in the largest waterway and was subject to legal recreational fishing, suggesting the magnitude of impacts of disturbance on populations occupying larger systems are reduced, and/or that recreational fishing hinders recovery rates following episodic disturbance events such as drought. Our results suggest that forecasting and management of long-lived freshwater fish must incorporate multi-year planning to include factors such as the maintenance of refuges, connectivity and increased protection of mature fish to aid recovery.
\end{abstract}

KEY WORDS: Drought - Endangered species - Macquarie perch - Recruitment - Recovery · Episodic disturbance $\cdot$ Long-lived fish $\cdot$ Climate change

\section{INTRODUCTION}

Episodic climatic events which extend across large regions can have profound effects, both positive and negative, on ecosystems and their populations (Labbe \& Fausch 2000, Vincenzi et al. 2016). The impacts of these events may be exacerbated where there is human-mediated habitat alteration (Bond \&

${ }^{*}$ Corresponding author: zeb.tonkin@delwp.vic.gov.au
Lake 2003, Driver \& Hoeinghaus 2016), and the frequency and severity of such events are predicted to increase due to climate change (e.g. Beniston et al. 2007, Balcombe et al. 2011, White et al. 2016). As such, the recovery of populations in the wake of such events need investigation to inform management strategies (Likens et al. 2009, Baumgartner et al. 2017).

() S.B., N.B., and Arthur Rylah Institute, Department for Environment, Land, Water and Planning 2019. Open Access under Creative Commons by Attribution Licence. Use, distribution and reproduction are unrestricted. Authors and original publication must be credited. 
Riverine fishes represent some of the most threatened taxa on the planet, due to one or a combination of anthropogenic threats including habitat degradation, altered hydrology, migration barriers, fisheries exploitation, introduction of invasive species and climate change (Cooke et al. 2012). Riverine fish populations can also be strongly influenced by episodic events such as extreme droughts and flood, by modifying important habitat or influencing survival of early life stages (e.g. Magoulick \& Kobza 2003, Bêche et al. 2009). The life history of many riverine fish are evolutionarily adapted to a system's flow regime, resulting in strong links between specific flow attributes and population processes (vital rates; Wootton 1998, Milner et al. 2003, Harris et al. 2013). These links range from the most basic requirement of fishesthat is, water of adequate quantity and quality for survival (e.g. Bradford \& Heinonen 2008, Bêche et al. 2009) - to more complex interactions between flow variability and habitat, and subsequent links to individual growth (Junk et al. 1989, Tonkin et al. 2017a), migration (Koster et al. 2017) and spawning (Dudley \& Platania 2007, King et al. 2016).

For many Australian riverine fish species, knowledge of the links between aspects of river flows and vital rates governing populations has improved markedly over the last decade, thereby improving planning and implementation of restoration actions (Koehn et al. 2014, King et al. 2016, Koster et al. 2017). Despite these advances, investigations of subsequent population changes are limited (but see Zampatti \& Leigh 2013, Tonkin et al. 2014). This is particularly the case for long-lived, late-maturing and dispersal-limited ( $K$-selected) species, which require data collected over long time periods, and ideally, for multiple populations given the gradual rates of population change (Hutchings et al. 2012, Vincenzi et al. 2016). As a result, the development of suitable management strategies for population outcomes for such species remains challenging.

Management of the nationally endangered Macquarie perch Macquaria australasica (Environmental Protection and Biodiversity Conservation Act 1999, Commonwealth; see https://www.legislation.gov.au/ Details/C2019C00275) is guided by data on a range of factors, including information on growth (Appleford et al. 1998, Tonkin et al. 2014), movement and home range (Ryan et al. 2013, Thiem et al. 2013, Koster et al. 2013), spawning (Cadwallader \& Rogan 1977, Tonkin et al. 2016) and recruitment (Tonkin et al. 2017b). A collective assessment of some of these processes was used to explore the recovery by a lacustrine population of Macquarie perch to a period of lake refilling in the wake of the 'millennium' drought (Tonkin et al. 2014), which persisted from 1997-2010 and was associated with record low streamflows in southeastern Australia (Murphy \& Timbal 2008). Unfortunately, information on survivorship of Macquarie perch recruits and subsequent population dynamics during the same postdrought period for remnant riverine populations remain limited. Given this lack of information, there is a clear need to assess population trends to better understand recovery rates of this threatened species.

This study investigated the population dynamics of 5 riverine Macquarie perch populations in southeastern Australia from 2007-2018, a period which encompassed extreme fluctuations in river flows at both landscape (during drought) and local scales. During this period, the abundance of Macquarie perch which recruited to young-of-year (YOY) varied considerably (Tonkin et al. 2017b). Nevertheless, whether these fish survived beyond this age to influence overall population growth and facilitate recovery in the wake of the aforementioned drought is unknown. Using data on relative abundance and size structure, we tested the following hypotheses: (1) Macquarie perch populations will show a general increasing trend in abundance following drought, with this response not occurring for several years due to the $K$ selected nature of the species; (2) the largest increases in abundance will be driven by new recruits into the population; (3) annual patterns in river flows will influence the magnitude of any such change due to its influence on recruitment dynamics (e.g. Tonkin et al. 2017b) and survival (e.g. Ruhi et al. 2016); and (4) patterns in dynamics among the geographically isolated populations will show some degree of synchrony given the landscape-scale influence of climate cycles (e.g. La Niña events; Verdon et al. 2004) in governing annual patterns of river flows and vital rates of populations (e.g. Koenig 2002, Tonkin et al. $2017 b$ ). Our results provide guidance for future management of this and other long-lived threatened freshwater fish species.

\section{MATERIALS AND METHODS}

\subsection{Study species}

Macquarie perch Macquaria australasica are a medium-sized (up to $465 \mathrm{~mm}$ total length [TL]; Lintermans 2007) percichthyid fish, once widespread and abundant across the southeastern reaches of the Murray-Darling Basin and several rivers of the east- 
ern seaboard (Tonkin et al. 2017b). This long-lived species (up to $30 \mathrm{yr}$; Tonkin et al. 2018) reaches full maturation at $3+$ yr of age, being age- rather than size-dependent (Appleford et al. 1998). Growth and size at maturity of Macquarie perch vary within and across habitat types, with food availability proposed to be a likely driver (Appleford et al. 1998, Tonkin et al. 2014, 2018). Recruitment to YOY is variable, depending on the abundance of mature fish and episodic high flow events during the spawning period, the latter being associated with poor survival of eggs and larvae (Tonkin et al. 2017b).

\subsection{Study sites and survey methods}

We explored the temporal patterns of Macquarie perch abundance and size structure between 2007 and 2018 across 5 waterways in southeastern Australia (Fig. 1). These populations have been routinely monitored over the last $10 \mathrm{yr}$. Each waterway received record low inflow during the millennium drought (Murphy \& Timbal 2008).

King Parrot, Hughes, Hollands and Seven creeks are unregulated tributaries of the Goulburn or Broken rivers. Details of these study systems and survey methods can be found in Tonkin et al. (2017b); how- ever, in brief: each has an annual average discharge of 40-60 $\mathrm{Ml} \mathrm{d}^{-1}$, with anthropogenic alterations to hydrology, connectivity and land-use resulting in highly fragmented habitats and isolated Macquarie perch populations (Pavlova et al. 2017, Tonkin et al. 2017b).

Annual fish surveys of the King Parrot and Hollands creeks were conducted between February and May from 2007-2018. Each year, between 5 and 7 sites were sampled in the King Parrot Creek using 1000-1200 s of backpack electrofishing (Smith-Root ${ }^{\circledR}$ Model 12 or 20b; Table 1, see Tonkin et al. 2017b). In Hollands Creek, 8 sites were surveyed each year using 1200 s of backpack electrofishing (SmithRoot ${ }^{\circledR}$ Model 12 or 20b). Backpack electrofishing surveys of Hughes and Seven creeks were conducted between January and May during 8 (Hughes: 5-12 sites) and 10 (Seven: 10-12 sites) of the years between 2006 and 2018. All fish captured were weighed (to the nearest $\mathrm{g}$ ) and measured for TL (nearest $\mathrm{mm}$ ) before release.

Unlike the other systems surveyed, the Yarra River is a coastal stream approximately $240 \mathrm{~km}$ in length, draining a catchment of approximately $3766 \mathrm{~km}^{2}$ (DWR 1989). Boat- (Smith-Root ${ }^{\circledR}$ Model 5 GPP) and bank-mounted (Smith-Root $7.5 \mathrm{kVa}$ ) electrofishing surveys have been conducted at multiple sites between January and June during 10 of the 12 years from

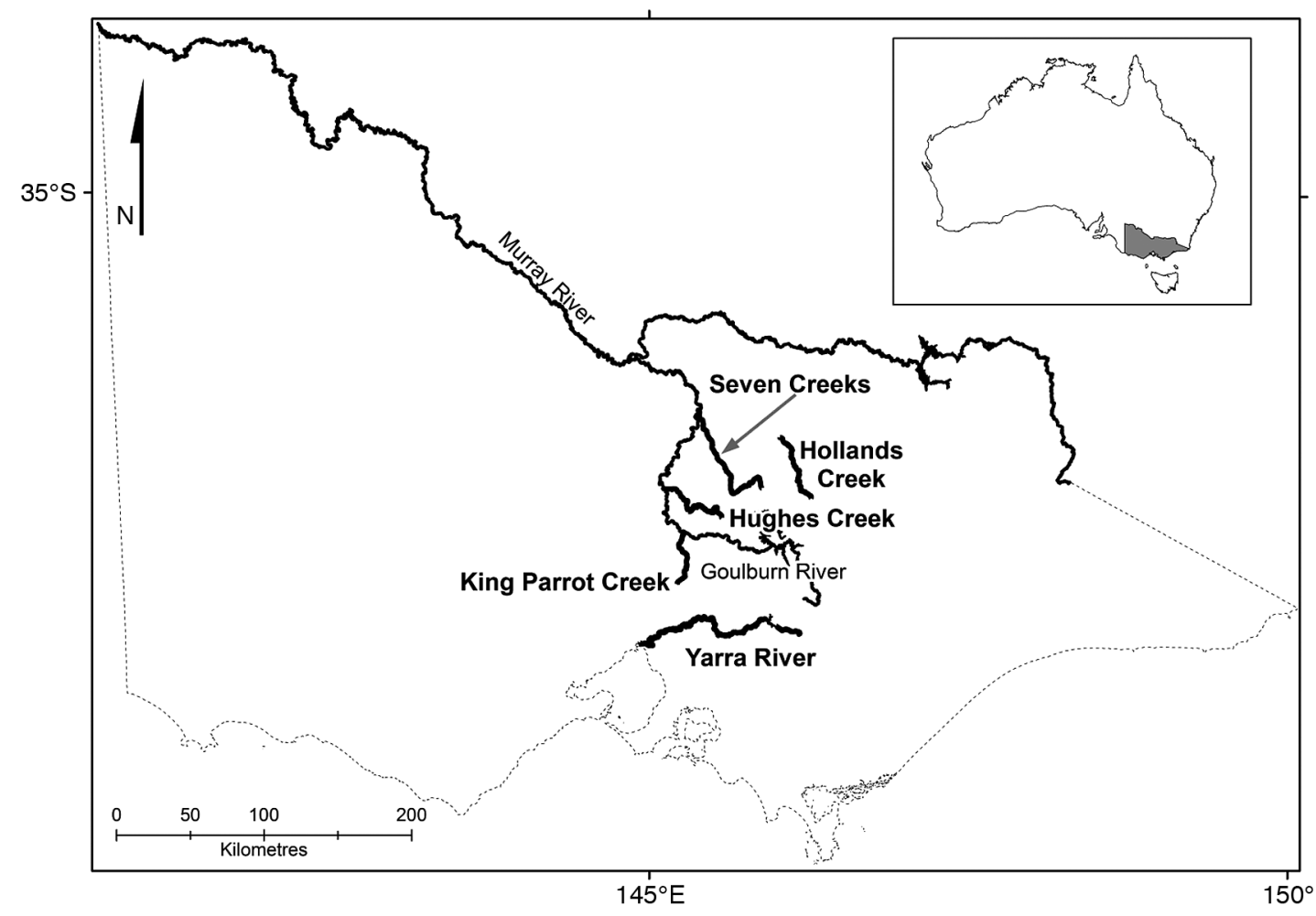

Fig. 1. The 5 waterways in Victoria, Australia subject to population monitoring of Macquarie perch 
2007-2018 (Table 1). Electrofishing at each site was undertaken by using a standardised protocol developed for the Sustainable Rivers Audit (Murray Darling Basin Commission 2004). Briefly, at each site, 12 replicate $90 \mathrm{~s}$ electrofishing shots were conducted across all habitats within the river channel. Two of the sites were often sampled using bank-mounted (Smith-Root 7.5 Kva) electrofishing using $10 \times 150 \mathrm{~s}$ shots (Sustainable Rivers Audit protocol) due to low flow periods.

\subsection{Data and site covariates}

As data were collated from various projects, data filtering processes were performed to control for potential sources of variation. First, to help control variation due to varying sampling efforts, total sampling time (using electrofishing seconds) was calculated for each event. Second, only sites that were sampled in 4 or more years were included in the analyses to help control for spatial variation. King Parrot Creek, Seven Creeks and Yarra River had several sites that sampled in 3 or fewer years and were therefore not used in the analysis. Third, most sites had annual visits around the same month to help control for seasonal sources of variation (e.g. temperature, annual population cycles; Table 1).

Daily discharge $\left(\mathrm{Ml} \mathrm{d}^{-1}\right)$ data were available for all rivers and the mid-reach of the Seven Creeks. As flow discharge are not comparable across waterways, data were standardised within each stream by dividing daily discharge data by the median value for the study period across all years. Thus, standardised flow data $<1$ indicates below median flow and vice versa for values $>1$. As sampling events occurred roughly annually, 3 flow metrics were developed to summarise the flow data between sampling events (using a single annual sampling event closest temporally to the median sampling month for that river; Table 1). They were low, median and high flow, defined as the $10^{\text {th }}, 50^{\text {th }}$ and $90^{\text {th }}$ percentile of mean daily discharge between sampling events, with these flow variables positively correlated (see Fig. 2).

\subsection{Analysis}

All Macquarie perch that were captured were assigned an estimated age using the published length-age relationships for riverine populations (Tonkin et al. 2017b). The population model was then performed for all Macquarie perch captured
Table 1. Electrofishing sampling events for each river used in the analysis, including the number of sites using electrofishing, number of distinct years sampled, and median month of the sampling event

\begin{tabular}{|lcccc|}
\hline River & $\begin{array}{c}\text { No. of } \\
\text { sites }\end{array}$ & $\begin{array}{c}\text { No. of } \\
\text { sampling } \\
\text { years }\end{array}$ & $\begin{array}{c}\text { Year } \\
\text { range }\end{array}$ & $\begin{array}{c}\text { Median } \\
\text { month }\end{array}$ \\
\hline Hollands Creek & 8 & 11 & $2008-2018$ & Jan \\
Hughes Creek & 7 & 10 & $2006-2018$ & Mar \\
King Parrot Creek & 5 & 9 & $2008-2018$ & Apr \\
Seven Creeks & 10 & 10 & $2007-2018$ & Mar \\
Yarra River & 5 & 10 & $2007-2018$ & Mar \\
\hline
\end{tabular}

which were estimated to be $>1$ yr of age (age 1+). All catches across all sites from a river were then summed together and the catch per unit effort (CPUE; in hours) was calculated. A state-space model was subsequently built to assess population trends over time across the 5 waterways (Kéry \& Schaub 2012). Using a state-space model allowed us to model both process and observation error variances. Ignoring process error has been shown to bias model selection such that covariates are often incorrectly selected (Maunder \& Watters 2003). Furthermore, state-space population models provide a more mechanistic process than other methods such as generalised additive models, which have been commonly used to analyse population count trends but rely on relatively arbitrary smoothing and do not partition process error from observation error. Loglinear models have also been extensively used to estimate changes between time periods but these do not link temporal steps nor do they handle missing abundance estimates.

For the state-process model, we used the log-linear population growth equation:

$$
\log \left(N_{t+1}\right)=\log \left(N_{t}\right)+r_{t}
$$

where $\mathrm{r}_{t} \sim \operatorname{Normal}\left(\bar{r}, \sigma_{r}^{2}\right) . N_{t}$ is the population metric (CPUE) at time t. $r_{t}$ is the stochastic population growth rate and $\bar{r}$ and $\sigma_{r}^{2}$ are the mean growth rate and the residual variation in population growth. As $r$ likely differs by river, we allowed each river to have its own average growth rate. We also tested for the effect of flow covariates on average annual growth rate. Due to strong correlations between metrics $(0.7$ to 0.9 ), we developed 4 models: (1) no flow variables; (2) low flow; (3) median flow; and (4) high flow. Since the effect of flow is likely nonlinear, we included a quadratic relationship between the flow metric and growth rate. The flow metrics were adjusted so that they were for the time between $t$ and $t+1$, thus 
Hollands Creek

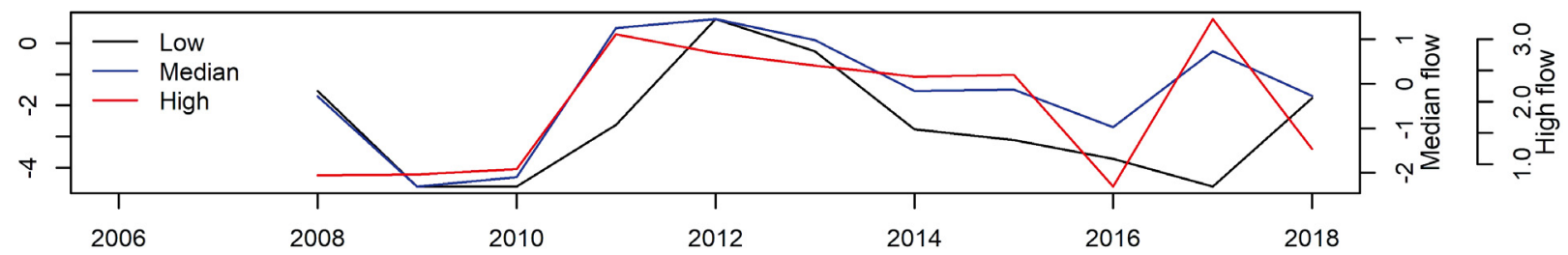

Hughes Creek

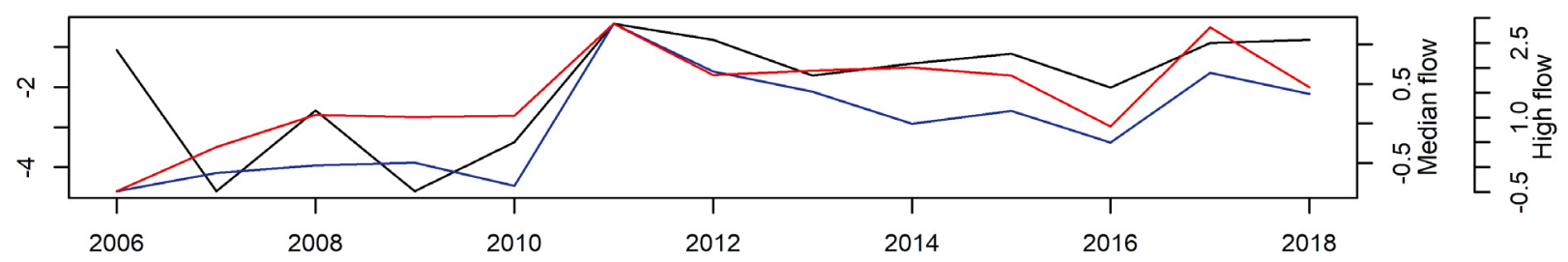

King Parrot Creek

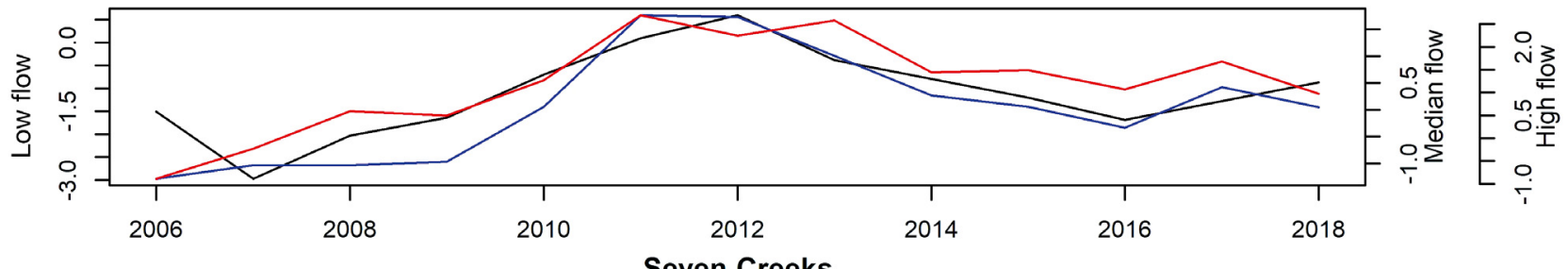

Seven Creeks

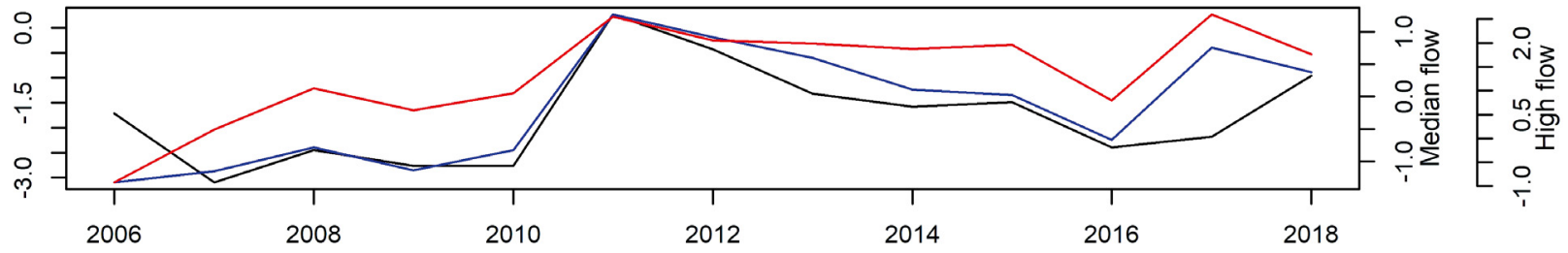

Yarra River

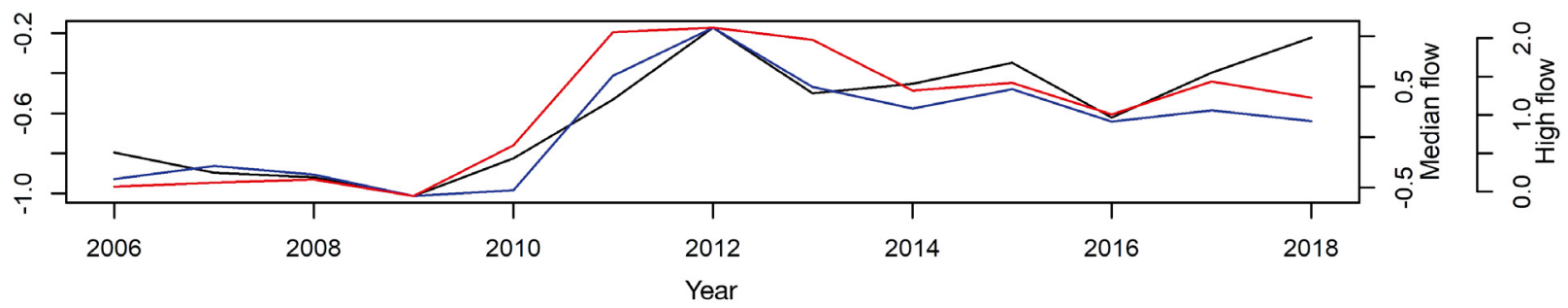

Fig. 2. Temporal plot for each flow metric for each waterway. Different line colours indicate a different flow metric. Low, median, and high flow are $10^{\text {th }}, 50^{\text {th }}$ and $90^{\text {th }}$ percentile for standardised flows for the previous $12 \mathrm{mo}$. Flow metrics have been transformed by a $\log (x+0.01)$ transformation. Note that each metric is on a different scale

reflecting our objective of assessing survival, including new recruits, entering the population. The growth rate

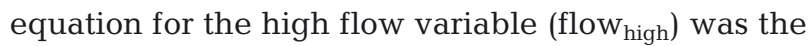
following:

$$
\overline{\mathrm{r}}_{\text {river }}=\mu_{\text {river }}+\text { flow }_{\text {high }} \times \beta_{1 \text {,river }}+\text { flow }^{2} \text { high } \times \beta_{2 \text {,river }}
$$

where $\mu_{\text {river }}$ is the average population growth rate for the river and $\beta_{1 \text {,river, }} \beta_{2 \text {,river }}$ are the model coefficients for the linear and quadratic effect of high flow.
For the observation model, we assumed that lognormal stochastic model:

$$
y_{t, \text { river }} \sim \operatorname{Normal}\left(\log \left(N_{t, \text { river }}\right), \sigma_{Y}^{2}\right)
$$

The model was solved by Markov chain Monte Carlo (MCMC) using R2jags (Su \& Yajima 2015). Uniform priors were used for all variance variables and noninformative normal priors for covariate variables. All models were checked for convergence using graphi- 
cal analyses and Gelman-Rubin measure of convergence. Posterior predictive checks were performed to assess model fit by comparing the discrepancy in the observed data with simulated data. Models were compared using deviance information criterion (DIC) and the best model(s) are presented below (see Table S1 in the Supplement at www.int-res.com/articles/suppl/ n040p257_supp.pdf for DIC values). Significant variables were defined as the highest posterior density not overlapping with zero.

The model performed here was a single agestructure model and focuses just on population growth for this one age group. Thus, population growth reflects recruitment (both birth and migration) and survival. Thus, increasing population size could be due to increased recruitment and/or increased survival (assuming some recruitment). Breaking apart these processes would require a multiple age-structure model to allow for recruitment and different survival rates for each age. Whilst advances have been made in using stage-structured models with unmarked populations (Zipkin et al. 2014), it is essential to get estimates of detection probabilities for each stage (e.g. age), as survival estimates become confounded with varying detection rates across stages. Given the threatened status of the species, we refrained from collecting annual age structure data, which requires sacrificing many fish for otolith samples. Instead, temporal patterns in fish length were modelled to enable an exploration of annual changes in population size structure in relation to any change in relative abundance (i.e. CPUE). This provides some indication on the contribution of juvenile fish recruiting into the population versus survival or immigration of existing larger fish in or into the sampled population. For example, a large increase in population size that was accompanied by a reduction in mean fish length within the lower size range reflects recruitment of YOY fish into the population (fish $>1$ yr of age). Conversely, an increase in population size but with no reduction in the lower size range is more likely to reflect no change in recruitment rates but rather an increase in survival of fish already accounted for in the population, or immigration of fish into the sample sites. To obtain these estimates, a quantile regression analysis was performed to model the $20^{\text {th }}, 50^{\text {th }}$ and $80^{\text {th }}$ percentile lengths for fish estimated to be $\geq 1 \mathrm{yr}$ of age (based on Tonkin et al. 2017b) assuming an asymmetric Laplace distribution. The quantile regression was performed using a Bayesian framework with the 'brms' package (Bürkner 2017). We built a model in which year-by-river was the categorical variable and length was the response variable.
Default non-informative priors were used. Convergence metrics and posterior predictive checks were assessed and found to meet the assumptions of the model. All analyses were performed using R v.3.3 (R Core Team 2017).

\section{RESULTS}

\subsection{Environmental variables}

The studied waterways exhibited similar patterns in annual discharge through time, particularly the creeks of the Goulburn-Broken catchments (Spearman correlation coefficients: 0.78-0.95; Figs. 2 \& S2a). All displayed a general trend of low annual flows from 2007-2010, followed by $2 \mathrm{yr}$ of high flows. The years 2013-2016 and 2018 exhibited average to low flows; 2017 was another period of high flows. Nevertheless, the smaller waterways of the Goulburn-Broken catchments exhibited more extreme flow variability, including several cease-toflow periods for some systems (e.g. Seven Creeks in 2016).

\subsection{Temporal trends in Macquarie perch abundance}

Macquarie perch abundance varied between and within the waterways though time (Fig. S1). Total catches across all years varied among the rivers, with $\mathrm{n}=328$ for Hollands Creek, $\mathrm{n}=491$ for Hughes Creek, n = 244 for King Parrot Creek, n = 958 for Seven Creeks, and $n=278$ for Yarra River. The temporal patterns in CPUE were similar for all rivers except the Yarra River. Specifically, fish abundance was low (with a stable or reducing trend) from 2007-2011, followed by overall positive growth rates in the period from 2013-2018 (Figs. 3, 4, \& S1).

Overall, the model that excluded flow covariates entirely, and the model that included just the high flow variable were best supported by the data ( DIC < 1). In contrast, the low and median flow models had less support (Table S1). The 2 models with strong support showed the same temporal patterns (as would be expected), but the high flow model predicted stronger effects of high flows. Therefore, we present the results from the high flow model below and in the figures. After a similar decline from 2007-2011, the Yarra River showed a steady CPUE across the years (growth rate $=-0.07$; $95 \%$ CI: $-0.4,0.27)$. The magnitude, and in some 

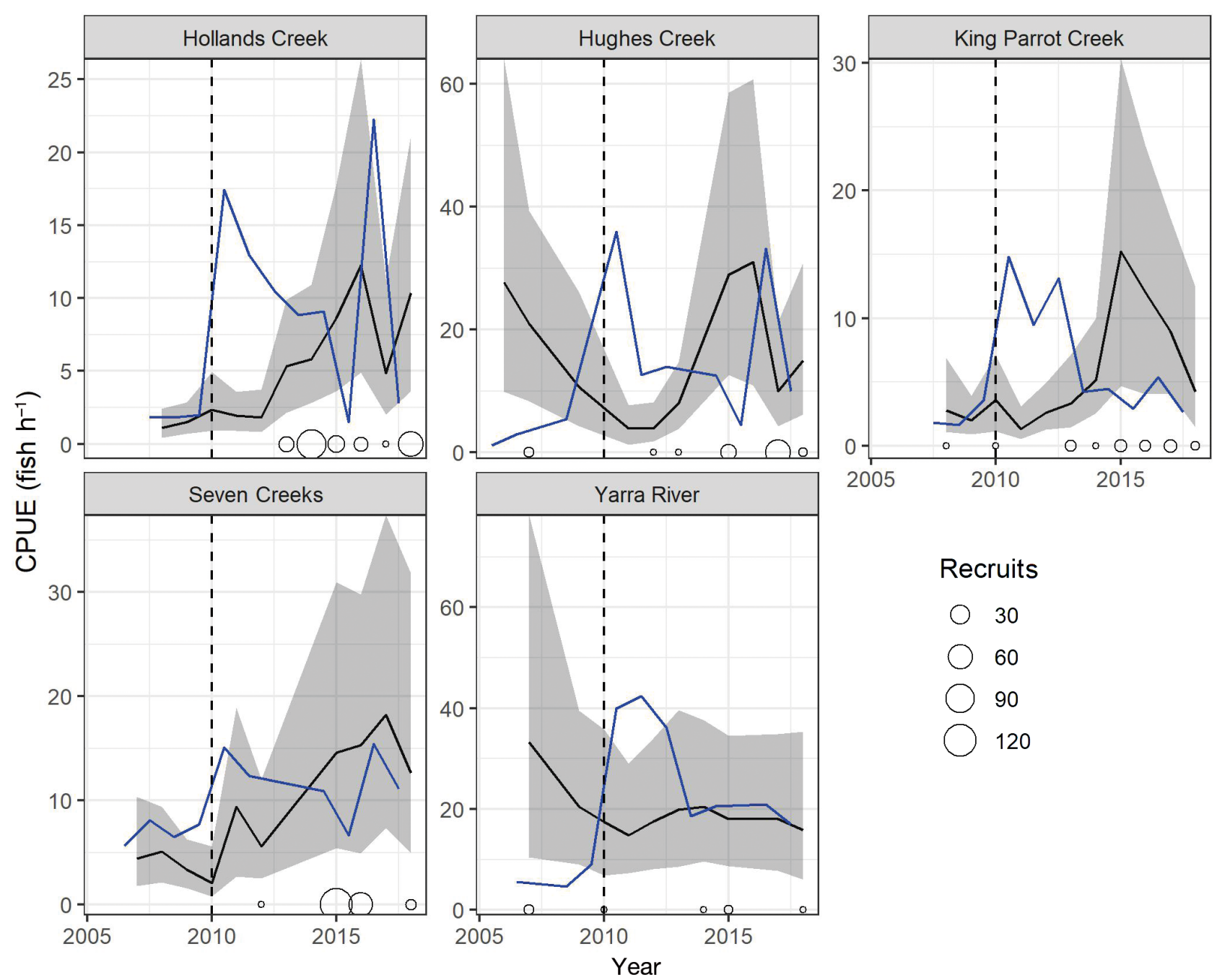

Fig. 3. Population trends for Macquarie perch (>age 1) for each waterway. Trends are presented as catch per unit effort (CPUE; number of fish captured per hour electrofishing time). Shaded area: $95 \%$ CI for the predicted CPUE; blue line: high flow pattern (upper $90^{\text {th }}$ percentile of mean daily flow); vertical dashed line: last summer of millennium drought. For reference in interpreting potential recruitment into the population, the CPUE of young-of-year recruits is shown as circles on the $x$-axis (with larger circles indicating higher CPUE)

cases, direction of annual changes in CPUE within the 2012-2018 period were variable between waterways and years. Most notably, Hughes Creek, King Parrot Creek and Hollands Creek all underwent steep reductions in CPUE in 2017 (Fig. 3), although estimates remained well above the levels recorded in the 2007-2011 period.

For the high flow model, the high flow variable, fitted as a quadratic term, was significant for 2 rivers: Hughes Creek and King Parrot Creek (Fig. 5). For these waterways, population growth rates were lower during extreme low (e.g. 2007-2010) and extreme high flow years (2011, 2012, 2017; Fig. 6). Hollands Creek showed a similar pattern, whilst the Yarra River and Seven Creeks showed a slight positive association between population growth and high flows (albeit non-significant).

\subsection{Temporal trends in Macquarie perch size structure}

Like trends in abundance, temporal patterns in fish length showed some similarities across waterways (Fig. 7). In general, the fish lengths in each of the size groups increased slightly from 2011-2013, after which time fish lengths declined within each of the size groups, particularly the lower $20^{\text {th }}$ percentile (Fig. 7, Table S2). This pattern, when viewed in association with regular occurrence of YOY recruits after 

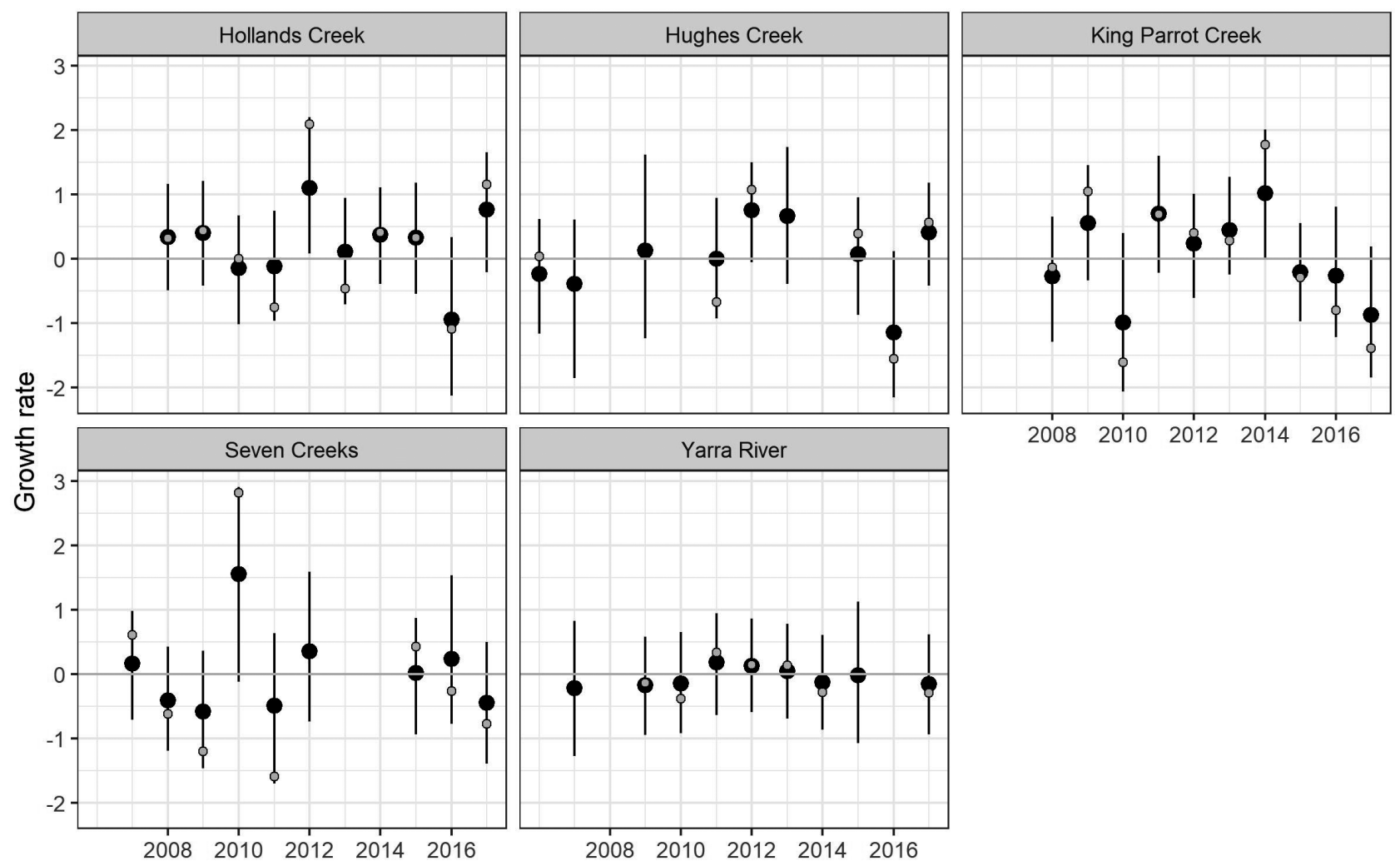

Fig. 4. Predicted yearly population growth rates (log-linear scale) for Macquarie perch in each river over time. Grey circles: estimated growth rate from the raw data. Modelled growth rates for sampled years are shown; raw growth rates are only shown when there were consecutive years of data. Error bars: $95 \% \mathrm{CI}$
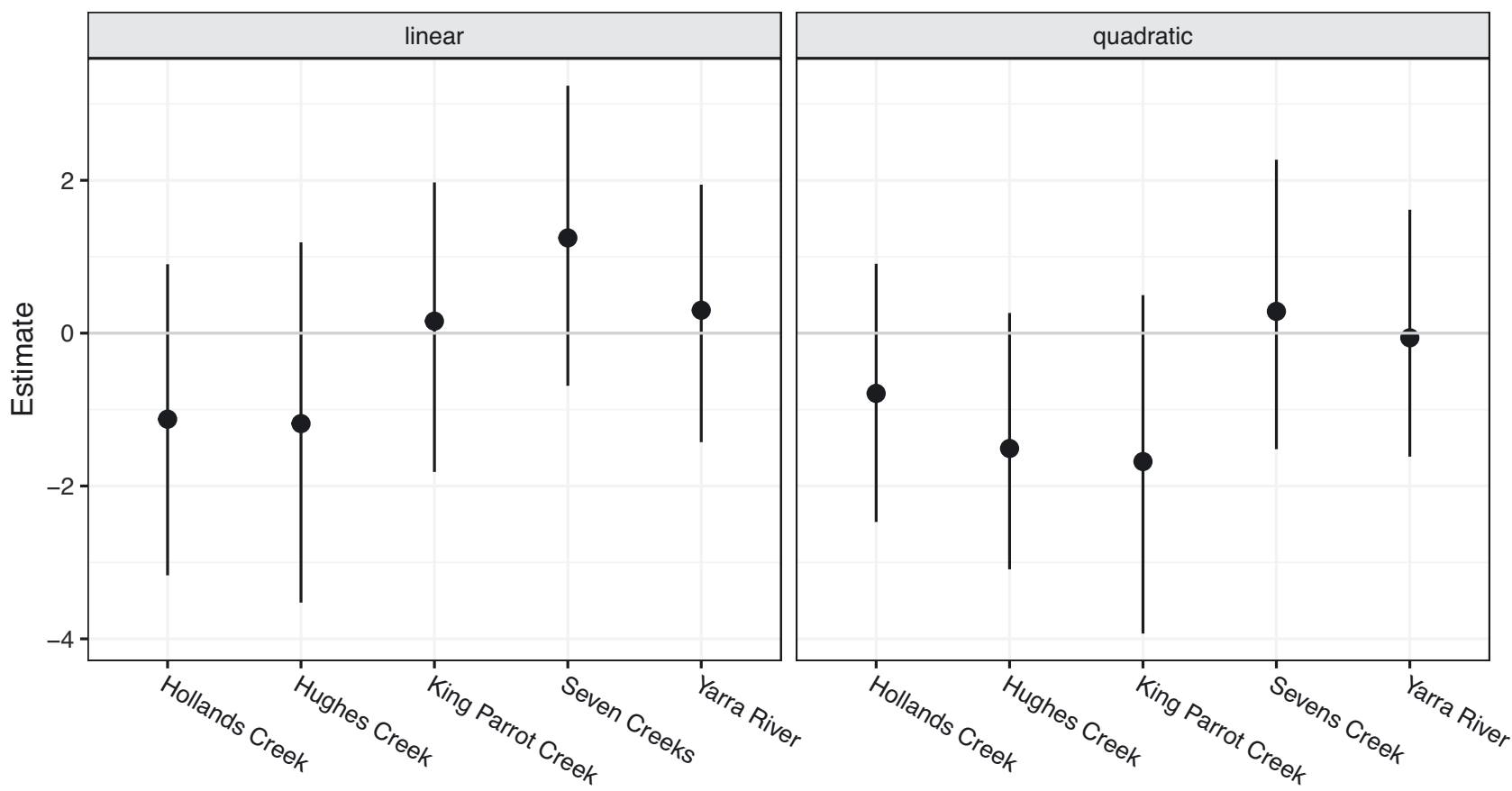

Fig. 5. Estimates of high flow (linear and quadratic) on Macquarie perch annual population growth rate (log-linear scale) for each river. Estimates are shown with $95 \%$ CI 

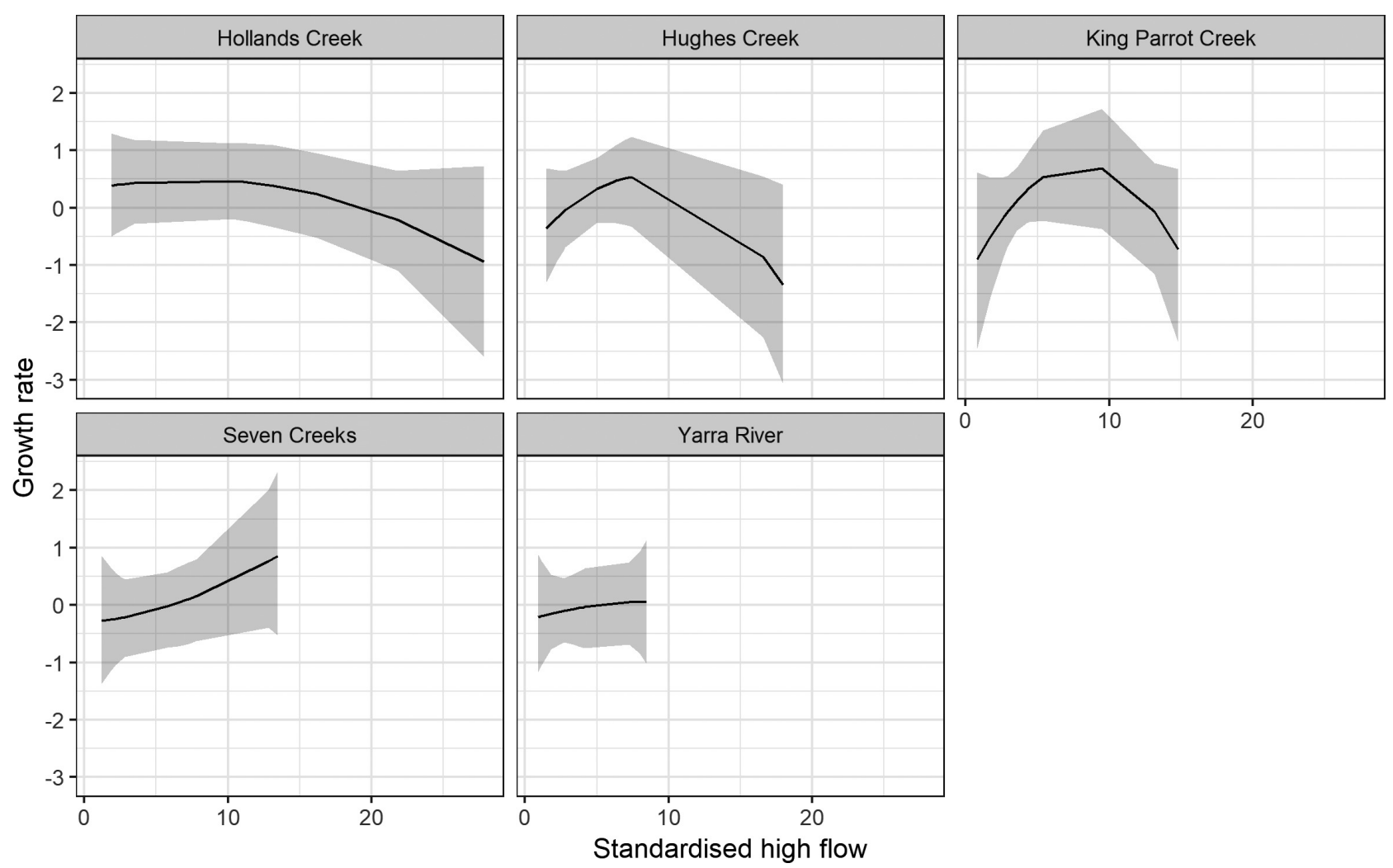

Fig. 6. Relationship between Macquarie perch annual population growth rate (log-linear scale) and standardised high daily flow $\left(\mathrm{Ml} \mathrm{d}^{-1}\right.$ transformed by a $\log [x+0.01]$ to allow comparison across systems). Estimates are shown with $95 \% \mathrm{CI}$

2013 (Figs. 3 \& 7), indicates that increased recruitment of juvenile fish into the population after 2013 was the main driver of the general increasing trends in fish abundance.

For some waterways and years, patterns between fish size and changes in abundance did not always fit this general pattern. In 2013, Hollands Creek showed a large increase in fish abundance; however, this was not mirrored by any change in fish size within the smaller size group, but rather by a large increase in both the $50^{\text {th }}$ and $80^{\text {th }}$ percentile size groups. This likely reflects increased survival of fish and immigration into the sample sites (given the low catch of fish in the upper size classes the previous year).

In 2017, several rivers experienced a decrease in fish population size (Fig. 3); however, the trends in size structure were not consistent across these rivers (Fig. 7). For both Hollands Creek and Hughes Creek, there was an increasing trend in all 3 size classes during this time coupled with a low (or absence) number of YOY recruits in both systems the previous year. Conversely, King Parrot Creek, which also underwent a large decline in CPUE in 2017 (also in 2016 and 2018), showed relatively stable patterns in the lower size class of fish and a large number of YOY recruits captured each year from 2013-2017.

For Seven Creeks, there were large decreases in fish lengths for all 3 size classes during 2016 and 2017, also coupled with high numbers of YOY recruits the preceding years (Fig. 7). This increase in juvenile fish was not, however, reflected in CPUE trends which were stable during this time (Fig. 3). Similarly, the Yarra River also showed large reductions in fish lengths for each of the size groups from 2015-2017, yet CPUE remained relatively stable.

\section{DISCUSSION}

Knowledge of the drivers, pathways and rates of population change form a crucial component of species management (e.g. Vincenzi et al. 2016). Our study documented the dynamics of 5 isolated populations of an imperilled riverine fish species. We collected data over a decadal period across a number of sites that were geographically isolated and encompassed extreme fluctuations in river flows at both landscape and local scales. Hence, we were able to 

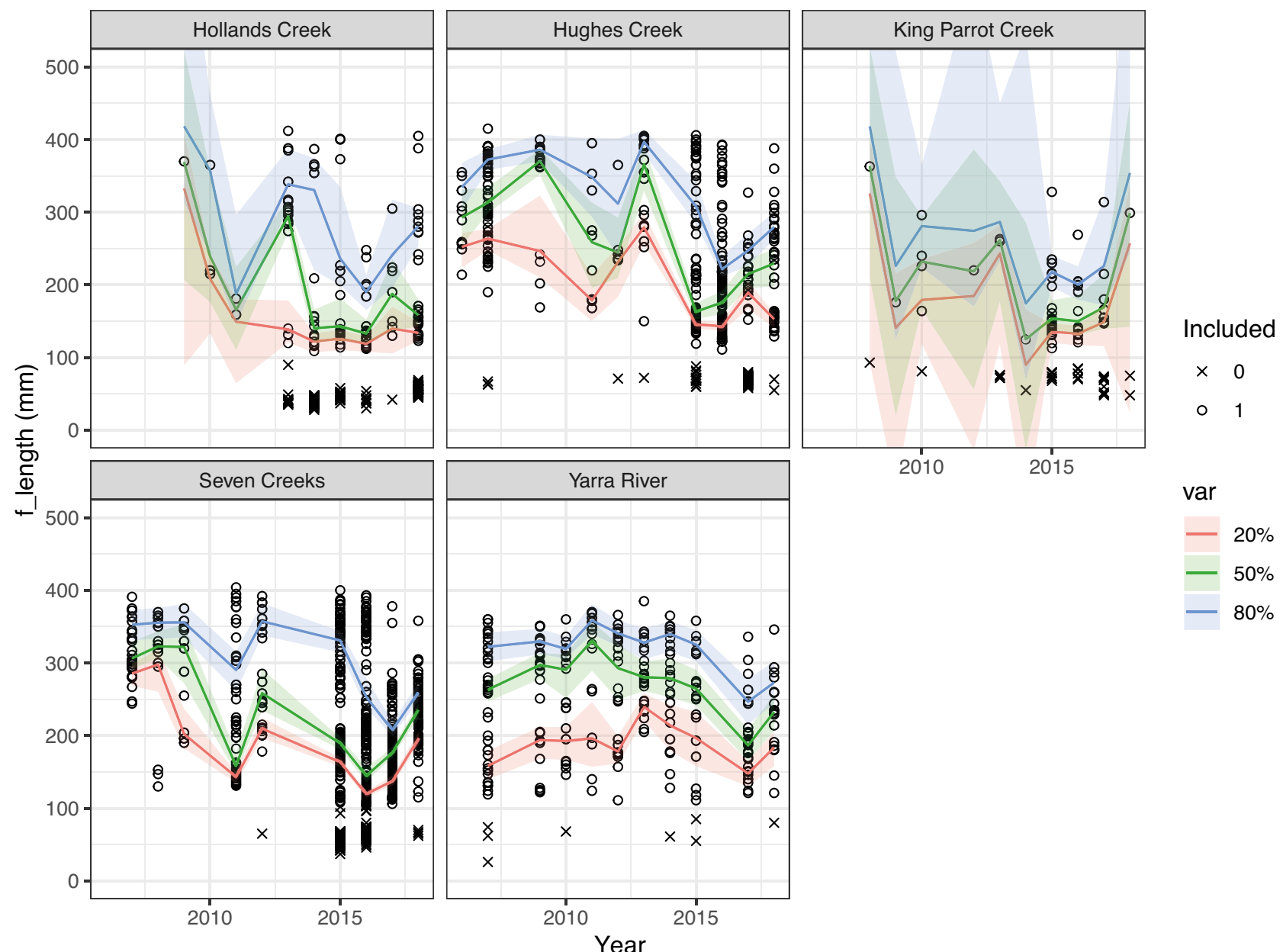

Fig. 7. Temporal patterns in Macquarie perch length $(\mathrm{mm})$ for each river. Different coloured lines show different percentile groups. Shaded area: $95 \%$ CI for each percentile. Raw fish lengths presented as open circles (used in the analysis), with $\times$ indicating young-of-year recruits (not used in the analysis)

explore the likely pathways, direction and rates of such trends across a broad spatial scale.

Macquarie perch Macquaria australasica populations in all waterways, except the Yarra River, showed similar trends in their dynamics. As hypothesised, the abundance of Macquarie perch showed an increasing trend in the years following the millennium drought, with population increases in most waterways not evident until 2-3 yr after drought conditions had subsided. Considering that our abundance estimates included fish $\geq 1$ yr of age, the recovery rates of adult fish, which reach full maturation at 3+ yr (Appleford et al. 1998), is likely to extend well beyond this time frame, with such gradual rates of recovery adhering to $K$-selected nature of the species (Hutchings et al. 2012, Whiterod et al. 2018). Of course the true extent of the impacts of the drought, and subsequent progress towards recovery, remain unknown, which unfortunately requires population data that preceded any impacts by the disturbance (e.g. Detenbeck et al. 1992).

Patterns in fish lengths indicated the survival of YOY recruits (identified in Tonkin et al. 2017b) was the key vital rate contributing to the largest increases in Macquarie perch abundance, occurring 2-3 yr post-drought. Furthermore, the trajectory of recovery was similar for 4 of the 5 isolated populations, particularly in the first $5 \mathrm{yr}$ following drought (Spearman correlation coefficients: $0.26-0.89$ for population change respectively; Fig. S2b). These populations were also the closest spatially and had the highest synchrony in river discharge (Fig. S2a). This trend was also comparable to that shown for a lacustrine population of Macquarie perch over the same time period (Tonkin et al. 2014). While the small number of waterways and their close proximity prevented any formal analysis, these results do provide some support for environmental synchrony (also known as the Moran effect; Moran 
1953, Koenig 2002), which predicts biotic and abiotic values co-vary across the landscape (Rossi et al. 1992, Liebhold et al. 2004). Such synchrony can be useful for managers to identify the regional-scale drivers of population variation of other freshwater species (e.g. Cattanéo et al. 2003, Tedesco et al. 2004, Bunnell et al. 2010). Regional-scale population synchrony is also likely to increase the vulnerability of isolated populations to simultaneous declines, therefore increasing the risk of regional populations becoming imperilled (e.g. Chevalier et al. 2015).

While there was a general increasing trend in Macquarie perch abundance for several years following drought in 4 of the 5 waterways, the magnitude, and in some cases, direction of annual change varied among waterways and years. This was despite patterns in river flow being highly correlated across waterways. As such, our hypothesis of annual patterns in river flows influencing the magnitude of population change was only partially supported by the analysis. There was some support for our model which included high flows, indicating reduced population growth the year following extreme low and also extreme high flow years. This finding is not in itself surprising. First, recruitment of some riverine fishes, including Macquarie perch, is affected by extreme changes in river flows during critical reproductive periods (e.g. Freeman et al. 2001, Nicola et al. 2009, Tonkin et al. 2017b). Second, very low flow rates can increase mortality of larger fish, particularly in smaller streams which are subject to rapid declines in water quality (e.g. Ruhi et al. 2016).

The weak association between annual flow and annual population change beyond the aforementioned extremes (i.e. flood and drought) suggests that intermediate variations in river flows may have a negligible influence on annual population change or are idiosyncratic in their effect within each waterway or on different life-stages. River flows interact with many other attributes including groundwater, geomorphology and biotic factors (e.g. predators) to influence the vital rates of a population (Humphries et al. 2019). Furthermore, the specifics of these attributes and their interactions are likely unique to a waterway or reach within. The role of flows in governing each vital rate may also differ. For example, while extreme high flows during spawning negatively impact Macquarie perch recruitment to YOY (Tonkin et al. 2017b), the same flows may provide an abundance of food for fish $\geq 1 \mathrm{yr}$ of age, thereby enhancing their growth, condition, survival and future reproductive output over extended timeframes (e.g. Gray et al. 2000, Tonkin et al. 2014).
The uncertainty in our models may also be due to variations in the detection of fish by our sampling regime, given that detection was not accounted for in our analysis. The sampling detection probability of fish can vary across environmental and biological gradients (Bayley \& Austen 2002, Speas et al. 2004, Lyon et al. 2014). While every effort was made to keep sampling consistent during our monitoring program (during low flow periods at a similar time of year), the uncertainty in our population models is likely to have been influenced by changes in sampling conditions or annual changes in Macquarie perch size and age structure.

The recovery pathway of populations following disturbance occurs through one or a combination of reproduction of surviving individuals and recolonisation (Bêche et al. 2009, Oliver et al. 2013). Given the isolated nature of the populations in the current study, the vital first step towards the recovery of Macquarie perch in each waterway was the local availability of refuges for the survival of fish throughout the drought period. While our study did not quantify the number of refuges in each system during extreme low-flow periods, the capture of fish in subsequent years does reflect the presence of these critical habitats. Such refugia are a vital attribute for population persistence in disturbed environments, particularly where rivers become disconnected, leaving fish vulnerable to a multitude of stressors (Lake 2003, Davey \& Kelly 2007).

The one system which did not adhere to our first prediction was the Yarra River. Like the other waterways, changes in the size structure of Macquarie perch in the Yarra River indicated that successful recruitment occurred from 2013-2015, yet the change in abundance since this time remained stable. We propose 2 hypotheses for this deviation from trends observed in the other systems. Firstly, discharge in the Yarra River is much less variable than the other systems (see Tonkin et al. 2017b). This may safeguard the population from episodic events such as extreme drought, whereby the magnitude of impacts are reduced compared to smaller, more variable systems (e.g. Lintermans 2013, Tonkin et al. 2017b). Nevertheless, we detected a declining trend in the last years of the drought which, like the other populations, suggests the drought period still had some impact on the Yarra River population.

Recovery is likely to be impaired if population decline exceeds critical intrinsic thresholds such as genetic loss (e.g. Pavlova et al. 2017) and/or Allee effects (Courchamp et al. 2008), or if existing management practices such as fishery regulations are inadequate 
(e.g. Whiterod et al. 2018). Whilst the rates of decline in the Yarra River did not appear to exceed those in the other study waterways, the latter pathway impairing recovery is plausible. The Yarra River is the only waterway in our study where Macquarie perch can be legally harvested (despite its conservation status). Indeed, the number of adult fish has reduced over the past $5 \mathrm{yr}$, with this trend likely to have flow-on effects on recruitment (Tonkin et al. 2017b). A recent investigation of a $K$-selected crayfish species highlighted how population recovery rates following major disturbance were severely reduced if existing harvest levels remained (Whiterod et al. 2018). As such, we suggest further investigation is needed to quantify recreational fishing levels and its potential impacts on recovery rates in the Yarra River population following episodic disturbance events such as drought (e.g. Hunt et al. 2011).

The results of our study also showed one example (Hollands Creek) in which total fish abundance was associated with an increase in the abundance of larger sized fish. This pattern may be due to the aforementioned variation in detection of these cohorts of fish the previous year or by immigration of larger fish into our sample sites. The latter, reflective of within-population redistribution, has been well documented in other studies, with fish movement shown to influence patterns in abundance within or between metapopulations (e.g. Palmer et al. 1997). Indeed, the movement of fish from refuges following disturbance events is particularly pertinent for the results of this study (e.g. Wootton 1998).

The findings of this study add to the increasing knowledge being collated on the ecology and risks to remaining populations of this threatened species. The results presented by Tonkin et al. (2017b) suggests most remnant populations of Macquarie perch, which are now predominantly isolated within small tributary systems characterised by highly variable flows, face a heightened risk of poor recruitment periods. These smaller systems are also more likely to experience greater variability in adult abundance as a result of increased vulnerability to stochastic events such as extreme drought, flood and bushfire (Kearns et al. 2011, Lintermans 2013). It could therefore be expected that with the loss of connectivity to larger rivers and the fish they once supported (Trueman 2011), Macquarie perch occupying these small tributary systems now exhibit less stable recruitment patterns (e.g. Tonkin et al. 2017b), population dynamics (this study) and a reduced resilience to environmental extremes, particularly those which are likely to be exacerbated by climate change (as predicted by Balcombe et al. 2011).
This study has made significant progress towards understanding the dynamics and drivers of populations of a nationally threatened riverine fish. Most significantly, the recovery of Macquarie perch populations following extended drought was not detectable for several years, with the largest increases in population size driven by the survival of new recruits. Our results indicate that future forecasting and management of this and other long-lived threatened freshwater fish species must incorporate multiyear planning, including the maintenance of refugia and connectivity (Crook et al. 2010). Further, the potential for population synchrony, whereby simultaneous declines of isolated populations increases the risk to species at a regional scale, should be considered along with the protection of reproductively mature fish (i.e. source populations). These strategies are all likely to become more important with time, particularly given the increased frequency and magnitude of episodic disturbance events predicted under climate change.

Acknowledgements. We thank Melbourne Water, the Goulburn-Broken Catchment Management Authority and the Department of Environment, Land, Water and Planning for project funding, support and provision of data. Thanks to the numerous staff from the Arthur Rylah Institute for data collection and curation throughout the sampling period; in particular, Justin O'Mahony, Jason Lieschke, Adrian Kitchingman, Andrew Pickworth, John Mahoney, Graeme Hackett, Alison King and Kris Pitman. Jon McGuckin and Tom Ryan are also thanked for their contribution to surveys of the Yarra River. John Koehn provided constructive comments on draft reviews. This work was carried out under the Victorian Fisheries Research Permit RP827, FFG Research Permit 10005913/10007273 and animal ethics approval 12/03.

\section{LITERATURE CITED}

Appleford P, Anderson TA, Gooley GJ (1998) Reproductive cycle and gonadal development of Macquarie perch, Macquaria australasica Cuvier (Percichthyidae), in Lake Dartmouth and tributaries of the Murray-Darling Basin, Victoria, Australia. Mar Freshw Res 49:163-169

Balcombe SR, Sheldon F, Capon SJ, Bond NR, Hadwen WL, Marsh N, Bernays SJ (2011) Climate-change threats to native fish in degraded rivers and floodplains of the Murray-Darling Basin. Mar Freshw Res 62:1099-1114

*Baumgartner LJ, Wooden IJ, Conallin J, Robinson W, Thiem JD (2017) Managing native fish communities during a long term drought. Ecohydrology 10:e1820

Bayley PB, Austen DJ (2002) Capture efficiency of a boat electrofisher. Trans Am Fish Soc 131:435-451

* Bêche LA, Connors PG, Resh VH, Merenlender AM (2009) Resilience of fishes and invertebrates to prolonged drought in two California streams. Ecography 32: 778-788

* Beniston M, Stephenson DB, Christensen OB, Ferro CA and others (2007) Future extreme events in European cli- 
mate: an exploration of regional climate model projections. Clim Change 81:71-95

Bond NR, Lake PS (2003) Characterizing fish habitat associations in streams as the first step in ecological restoration. Austral Ecol 28:611-621

Bradford MJ, Heinonen JS (2008) Low flows, instream flow needs and fish ecology in small streams. Can Water Resour J 33:165-180

* Bunnell DB, Adams JV, Gorman OT, Madenjian CP, Riley SC, Roseman EF, Schaeffer JS (2010) Population synchrony of a native fish across three Laurentian Great Lakes: evaluating the effects of dispersal and climate. Oecologia 162:641-651

Bürkner P (2017) brms: an R package for Bayesian multilevel models using Stan. J Stat Softw 80:1-28

Cadwallader PL, Rogan PL (1977) The Macquarie perch, Macquaria australasica (Pisces: Percichthyidae) of Lake Eildon, Victoria. Aust J Ecol 2:409-418

Cattanéo F, Hugueny B, Lamouroux N (2003) Synchrony in brown trout, Salmo trutta, population dynamics: a 'Moran effect'on early life stages. Oikos 100:43-54

* Chevalier M, Laffaille P, Ferdy JB, Grenouillet G (2015) Measurements of spatial population synchrony: influence of time series transformations. Oecologia 179:15-28

Cooke SJ, Paukert C, Hogan Z (2012) Endangered river fish: factors hindering conservation and restoration. Endang Species Res 17:179-191

Courchamp F, Berec L, Gascoigne J (2008) Allee effects in ecology and conservation. Oxford University Press, Oxford

Crook DA, Reich P, Bond NR, McMaster D, Koehn JD, Lake PS (2010) Using biological information to support proactive strategies for managing freshwater fish during drought. Mar Freshw Res 61:379-387

* Davey AJ, Kelly DJ (2007) Fish community responses to drying disturbances in an intermittent stream: a landscape perspective. Freshw Biol 52:1719-1733

Detenbeck NE, DeVore PW, Niemi GJ, Lima A (1992) Recovery of temperate-stream fish communities from disturbance: a review of case studies and synthesis of theory. Environ Manage 16:33-53

* Driver LJ, Hoeinghaus DJ (2016) Spatiotemporal dynamics of intermittent stream fish metacommunities in response to prolonged drought and reconnectivity. Mar Freshw Res 67:1667-1679

Dudley RK, Platania SP (2007) Flow regulation and fragmentation imperil pelagic spawning riverine fishes. Ecol Appl 17:2074-2086

DWR (Department of Water Resources) (1989) Water Victoria: a resource handbook. Department of Water Resources, Victoria

Freeman MC, Bowen ZH, Bovee KD, Irwin ER (2001) Flow and habitat effects on juvenile fish abundance in natural and altered flow regimes. Ecol Appl 11:179-190

* Gray SC, De Silva SS, Ingram BA, Gooley GJ (2000) Effects of river impoundments on body condition and reproductive performance of the Australian native fish, Macquarie perch (Macquaria australasica). Lakes Reservoirs: Res Manage 5:281-291

Harris JH, Bond N, Closs GP, Gerhke PC, Nicol SJ, Ye Q (2013) Dynamics of populations. In: Humphries P, Walker $\mathrm{K}$ (eds) Ecology of Australian freshwater fishes. CSIRO Publishing, Melbourne, p 223-244

Humphries P, King AJ, McCasker N, Kopf RK, Stoffels R, Zampatti BP, Price AE (2019) Riverscape recruitment: a conceptual synthesis of drivers of fish recruitment in rivers. Can J Fish Aquat Sci, doi:10.1139/cjfas-2018-0138

*Hunt TL, Douglas JW, Allen MS, Gwinn DC, Tonkin Z, Lyon J, Pickworth A (2011) Evaluation of population decline and fishing sustainability of the endangered Australian freshwater fish Macquaria australasica. Fish Manag Ecol 18:513-520

* Hutchings JA, Myers RA, García VB, Lucifora LO, Kuparinen A (2012) Life history correlates of extinction risk and recovery potential. Ecol Appl 22:1061-1067

Junk W, Bayley PB, Sparks RE (1989) The flood pulse concept in river-floodplain systems. Publ Spec Can Sci Halieut Aquat 106:110-127

Kearns J, Ayres R, O'Mahony J, Hackett G, Lyon J (2011) An investigation into Macquarie perch and trout cod populations in the Goulburn-Broken Catchment and their response to increased flows during 2010/2011. Confidential Client Report prepared for the Goulburn-Broken Catchment Authority. Department of Sustainability and Environment, Melbourne

Kéry M, Schaub M (2012) Bayesian population analysis using WinBUGS: a hierarchical perspective. Academic Press, San Diego, CA

King AJ, Gwinn DC, Tonkin Z, Mahoney J, Raymond S, Beesley L (2016) Using abiotic drivers of fish spawning to inform environmental flow management. J Appl Ecol 53: 34-43

Koehn JD, King AJ, Beesley L, Copeland C, Zampatti BP, Mallen Cooper M (2014) Flows for native fish in the Murray Darling Basin: lessons and considerations for future management. Ecol Manage Restor 15:40-50

Koenig WD (2002) Global patterns of environmental synchrony and the Moran effect. Ecography 25:283-288

Koster WM, Dawson DR, Morrongiello JR, Crook DA (2013) Spawning season movements of Macquarie perch (Macquaria australasica) in the Yarra River, Victoria. Aust J Zool 61:386-394

Koster WM, Dawson DR, Liu C, Moloney PD, Crook DA, Thomson JR (2017) Influence of streamflow on spawning related movements of golden perch Macquaria ambigua in south eastern Australia. J Fish Biol 90: 93-108

* Labbe TR, Fausch KD (2000) Dynamics of intermittent stream habitat regulate persistence of a threatened fish at multiple scales. Ecol Appl 10:1774-1791

Lake PS (2003) Ecological effects of perturbation by drought in flowing waters. Freshw Biol 48:1161-1172

Liebhold A, Koenig WD, Bjørnstad ON (2004) Spatial synchrony in population dynamics. Annu Rev Econ 35: 467-490

Kikens GE, Walker KF, Davies PE, Brookes J and others (2009) Ecosystem science: toward a new paradigm for managing Australia's inland aquatic ecosystems. Mar Freshw Res 60:271-279

Lintermans M (2007) Fishes of the Murray-Darling Basin: an introductory guide. Murray Darling Basin Commission, Canberra

* Lintermans M (2013) The rise and fall of a translocated population of the endangered Macquarie perch, Macquaria australasica, in south-eastern Australia. Mar Freshw Res 64:838-850

K Lyon JP, Bird T, Nicol S, Kearns J and others (2014) Efficiency of electrofishing in turbid lowland rivers: implications for measuring temporal change in fish populations. Can J Fish Aquat Sci 71:878-886 
Magoulick DD, Kobza RM (2003) The role of refugia for fishes during drought: a review and synthesis. Freshw Biol 48:1186-1198

Maunder MN, Watters GM (2003) A general framework for integrating environmental time series into stock assessment models: model description, simulation testing, and example. Fish Bull 101:89-99

Milner NJ, Elliott JM, Armstrong JD, Gardiner R, Welton JS, Ladle M (2003) The natural control of salmon and trout populations in streams. Fish Res 62:111-125

Moran PAP (1953) The statistical analysis of the Canadian lynx cycle. II. Synchronization and meteorology. Aust J Zool 1:291-298

Murphy BF, Timbal B (2008) A review of recent climate variability and climate change in southeastern Australia. Int J Climatol 28:859-879

Murray-Darling Basin Commission (2004) Sustainable rivers audit-pilot audit: fish theme technical report. MDBC Publication No. 6(04). Murray-Darling Basin Commission, Canberra

Nicola GG, Almodóvar A, Elvira B (2009) Influence of hydrologic attributes on brown trout recruitment in low-latitude range margins. Oecologia 160:515-524

Oliver TH, Brereton T, Roy DB (2013) Population resilience to an extreme drought is influenced by habitat area and fragmentation in the local landscape. Ecography 36: 579-586

Palmer MA, Ambrose RF, Poff NL (1997) Ecological theory and community restoration ecology. Restor Ecol 5:291-300

* Pavlova A, Beheregaray LB, Coleman R, Gilligan D and others (2017) Severe consequences of habitat fragmentation on genetic diversity of an endangered Australian freshwater fish: a call for assisted gene flow. Evol Appl 10:531-550

R Core Team (2017) R: a language and environment for statistical computing. R Foundation for Statistical Computing, Vienna

Rossi RE, Mulla DJ, Journel AG, Franz EH (1992) Geostatistical tools for modeling and interpreting ecological spatial dependence. Ecol Monogr 62:277-314

Ruhi A, Olden JD, Sabo JL (2016) Declining streamflow induces collapse and replacement in the American Southwest. Front Ecol Environ 14:465-472

Ryan KA, Lintermans M, Ebner BC, Norris R (2013) Using fine-scale overlap in predator-prey distribution to assess avian predation risk to a reservoir population of threatened Macquarie perch. Freshw Sci 32:1057-1072

Speas DW, Walters CJ, Ward DL, Rogers RS (2004) Effects of intraspecific density and environmental variables on electrofishing catchability of brown and rainbow trout in the Colorado River. N Am J Fish Manage 24:586-596

Su Y, Yajima M (2015) R2jags: using R to run 'JAGS'. R package version 0.5-7. https://CRAN.R-project.org/ package=R2jags

Tedesco PA, Hugueny B, Paugy D, Fermon Y (2004) Spatial synchrony in population dynamics of West African fishes:

Editorial responsibility: Eduardo Martins,

Vancouver, British Columbia, Canada a demonstration of an intraspecific and interspecific Moran effect. J Anim Ecol 73:693-705

*Thiem JD, Broadhurst BT, Lintermans M, Ebner BC, Clear RC, Wright D (2013) Seasonal differences in the diel movements of Macquarie perch (Macquaria australasica) in an upland reservoir. Ecol Freshwat Fish 22:145-156

*Tonkin Z, Lyon J, Ramsey D, Bond N and others (2014) Reservoir refilling enhances growth and recruitment of an endangered remnant riverine fish. Can J Fish Aquat Sci 71:1888-1899

Tonkin Z, Kearns J, O'Mahony J, Mahoney J (2016) Spatiotemporal spawning patterns of two riverine populations of the threatened Macquarie perch (Macquaria australasica). Mar Freshw Res 67:1762-1770

*Tonkin Z, Kitchingman A, Lyon J, Kearns J and others (2017a) Flow magnitude and variability influence growth of two freshwater fish species in a large regulated floodplain river. Hydrobiologia 797:289-301

Tonkin Z, Kearns J, Lyon J, Balcombe S, King A, Bond N (2017b) Regional scale extremes in river discharge and localised spawning stock abundance influence recruitment dynamics of a threatened freshwater fish. Ecohydrology 10:e1842

Tonkin Z, Lyon J, Moloney P, Balcombe SR, Hackett G (2018) Spawning stock characteristics and migration of a lake bound population of the endangered Macquarie perch Macquaria australasica. J Fish Biol 93:630-640

Trueman WT (2011) True tales of the trout cod: river histories of the Murray-Darling Basin. Murray-Darling Basin Authority Publication No. 215/11. Murray-Darling Basin Authority, Canberra

*Verdon D, Wyatt AM, Kiem AS, Franks SW (2004) Multidecadal variability of rainfall and streamflow: Eastern Australia. Water Resour Res 40:W10201

* Vincenzi S, Mangel M, Jesensek D, Garza JC, Crivelli AJ (2016) Within and among population variation in vital rates and population dynamics in a variable environment. Ecol Appl 26:2086-2102

*White RS, McHugh PA, McIntosh AR (2016) Drought survival is a threshold function of habitat size and population density in a fish metapopulation. Glob Change Biol 22:3341-3348

*Whiterod NS, Zukowski S, Asmus M, Todd CR, Gwinn DC (2018) Take the long way home: minimal recovery in a Kselected freshwater crayfish impacted by significant population loss. Ecol Indic 89:622-630

Wootton RJ (1998) Ecology of teleost fishes, $2^{\text {nd }}$ edn. Kluwer Academic Publishers, Dordrecht

Zampatti B, Leigh S (2013) Effects of flooding on recruitment and abundance of golden perch (Macquaria ambigua ambigua) in the lower River Murray. Ecol Manage Restor 14:135-143

K Zipkin EF, Thorson JT, See K, Lynch HJ and others (2014) Modelling structured population dynamics using data from unmarked individuals. Ecology 95:22-29

Submitted: April 8, 2019; Accepted: September 30, 2019 Proofs received from author(s): December 2, 2019 